\title{
A MOLECULAR AND HAEMATOLOGICAL STUDY OF THEILERIA EQUI IN BALKAN DONKEYS
}

\author{
Dajana DAVITKOV ${ }^{1}$, Darko DAVITKOV ${ }^{2 *}$, Milos VuCICEVIC ${ }^{2}$, Ljubodrag STANISIC $^{3}$, \\ Milena RADAKOVIC ${ }^{1}$, Uros GLAVINIC ${ }^{1}$ and Zoran STANIMIROVIC ${ }^{1}$ \\ ${ }^{1}$ Department of Biology, Faculty of Veterinary Medicine, University of Belgrade, \\ Belgrade, Serbia; ${ }^{2}$ Department of Equine, Small Animal, Poultry and Wild Animal \\ Diseases, Faculty of Veterinary Medicine, University of Belgrade, Bul. oslobodjenja 18, \\ 11000 Belgrade, Serbia; ${ }^{3}$ Department of Obstetrics, Sterility and A. I., Faculty of \\ Veterinary Medicine, University of Belgrade, Belgrade, Serbia
}

(Received 15 December 2016; accepted 4 April 2017)

\begin{abstract}
Equine piroplasmosis in donkeys has been recognised as a serious problem of major economic importance. The present molecular study is the first investigation of the presence of Theileria equi and Babesia caballi in Balkan donkeys and of the possible haematological alterations related to it. A total of 70 apparently healthy donkeys from Serbia were included in this study. The overall prevalence of $T$. equi infection in donkeys tested with multiplex PCR was $50 \%$. There was no $B$. caballi-positive sample. Infections in donkeys included in this study seem to be associated with decreased red blood cell count, haemoglobin concentration, haematocrit and platelet count, and with increased white blood cell count, mean corpuscular haemoglobin and mean corpuscular haemoglobin concentration. Altered haematological parameters in donkeys can lead to a decrease in working capacity and production performance. Further molecular research and long-term monitoring of equine piroplasmosis is needed in Serbia and throughout Europe.
\end{abstract}

Key words: Equine piroplasmosis, donkeys, PCR, haematological alterations, Serbia

The Balkan donkey is an endangered autochthonous breed confined to the Balkans and viewed as an unselected, unstructured population threatened by depopulation, inbreeding and stochastic traditional management (Stanisic et al., 2015). Reduction in the size of the population over the last decades came as a result of intensive agrarian production and modern farming trends. Due to additional socioeconomic changes in the rural areas, the current number of sexually mature donkeys in Serbia has been estimated at 250-300 individuals only (Stanisic et al., 2015). Over the past few years, interest in the welfare and diseases of donkeys has been constantly increasing due to the rediscovery of donkey milk and its different uses as well as due to the use of donkeys in sports activities, for rec-

\footnotetext{
"Corresponding author; E-mail: davitkov@vet.bg.ac.rs; Phone/Fax: 00381 (11) 3611-809
} 
reational purposes, donkey-assisted therapy, as pack/draught animals and for meat production (Wise et al., 2013; Laus et al., 2015).

Equine piroplasmosis (EP) is one of the most important tick-borne disease in equids (horses, donkeys, mules and zebras) caused by the intraerythrocytic haemoprotozoan parasites Theileria equi and Babesia caballi (Mehlhorn and Schein, 1998; Kumar et al., 2009). EP has a worldwide distribution and is endemic in tropical, subtropical and some temperate regions (Rothschild, 2013). Piroplasmosis in donkeys has been recognised as a serious problem of major economic importance since the affected animals manifest loss of appetite and decreased working capacity. Donkeys usually show an asymptomatic form of the disease (chronic cases), with lower parasitaemia compared to infection in horses (Kumar et al., 2009). Acute cases of piroplasmosis in donkeys are characterised by fever, listlessness, depression, noticeable thirst, swelling of the eyelids, constipation, presence of a yellow mucus covering the faeces, yellowish coloration of the urine, and splenomegaly (Laus et al., 2015). Chronic cases are usually characterised by nonspecific clinical signs such as mild inappetence, poor work performance and weight loss (Kumar et al., 2009).

So far only a single study has been conducted in Serbia about equine piroplasmosis in horses (Davitkov et al., 2016), and there is no report on the presence or prevalence of these parasites in donkeys in this region. The present study is the first molecular investigation aimed to examine the presence of $T$. equi and $B$. caballi in Balkan donkeys in Serbia, and to investigate the possible haematological alterations related to it.

\section{Materials and methods}

\section{Donkeys, sampling procedures and haematology analyses}

The majority of the donkey population in Serbia is situated in the following locations: the Special Nature Reserve (SNR) 'Zasavica', the Stara planina Mt. region and in Kovilj village near Novi Sad (Fig. 1) (Stanisic et al., 2015). A total of 70 apparently healthy donkeys from these three locations were included in this study: 25 donkeys from SNR Zasavica, 25 donkeys from Stara planina Mt. and 20 donkeys from Kovilj village. Blood samples were collected by jugular venipuncture into sterile tubes with anticoagulant (EDTA) for polymerase chain reaction (PCR) and complete blood count (CBC). Stress was minimised by handling the animals with care before the collection of samples. The samples were maintained under cool conditions and immediately transferred to the laboratory. Haematological profiles were performed within $12 \mathrm{~h}$ following the blood sampling. CBC was determined with an automatic cell counter (Abacus Junior Vet, Diatron, Austria), using the pre-formatted software for analysing equine blood. The following parameters were included in the haematological analysis: white blood cells (WBC), lymphocytes (LYM), mid cells count (MID), granulo- 
cytes (GRA), red blood cells (RBC), haemoglobin (HGB), hematocrit (HCT), mean corpuscular haemoglobin $(\mathrm{MCH})$, mean corpuscular haemoglobin concentration (MCHC), mean corpuscular volume (MCV) and platelet count (PLT).

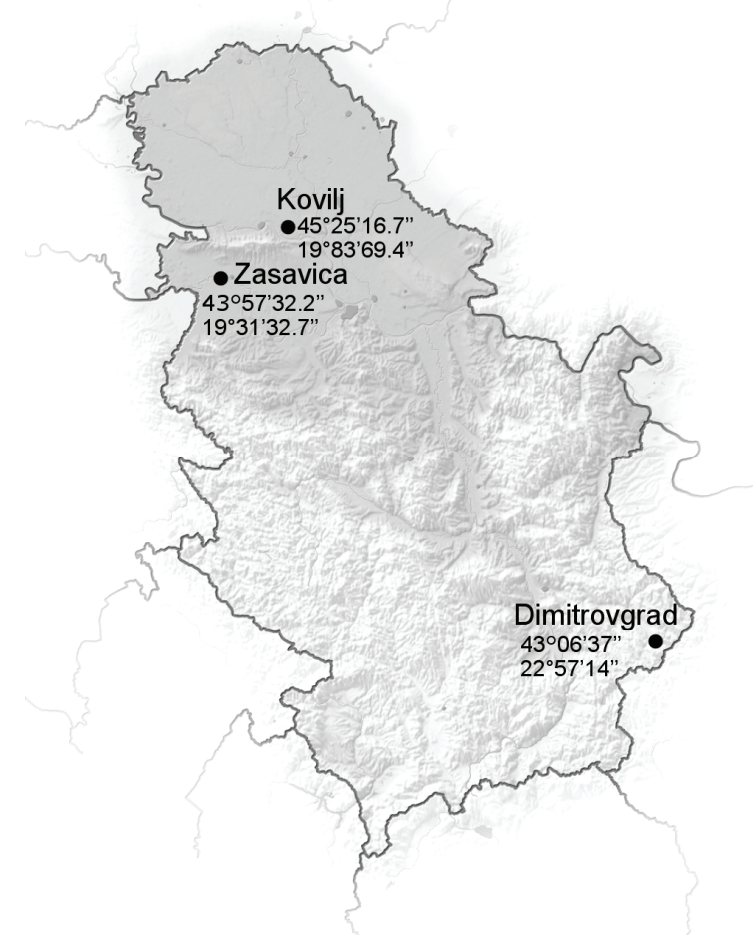

Fig. 1. Map of Serbia: the black dots indicate localities were samples were collected

\section{DNA extraction and multiplex PCR}

DNA was isolated from the blood samples using QIAamp DNA Blood Mini Kit (Qiagen, Hilden, Germany) according to the manufacturer's recommendations. Extracted DNA samples were stored at $-20{ }^{\circ} \mathrm{C}$ until use. A multiplex PCR method for the simultaneous detection and differentiation of $T$. equi and $B$. caballi was employed with the following set of primers: Bec-UF2 as a universal forward primer and Cab-R and Equi-R as reverse primers specific for B. caballi and T. equi, respectively (Alhassan et al., 2005). This set of primers amplifies specific fragments of the 18S rRNA gene (392 bp for T. equi, $540 \mathrm{bp}$ for $B$. caballi).

All PCRs were performed in a MultiGene Gradient Thermal Cycler (Labnet International Inc., Edison, NJ, USA) in $25-\mu \mathrm{L}$ volumes containing $12.5 \mu \mathrm{L}$ of KAPA2G Robust HotStart ReadyMix (Kapa Biosystems, Wilmington, Massachusetts, USA, PN KK7152), $1.25 \mu \mathrm{L}$ of each primer $(10 \mu \mathrm{M})$ and $10 \mu \mathrm{L}(10 \mathrm{ng} / \mu \mathrm{L})$ 
DNA sample. The PCR parameters for amplification were: initial DNA denaturation of 3 min at $95^{\circ} \mathrm{C}$ followed by 35 cycles of $15 \mathrm{~s}$ at $95^{\circ} \mathrm{C}, 15 \mathrm{~s}$ at $58{ }^{\circ} \mathrm{C}$ and $15 \mathrm{~s}$ at $72{ }^{\circ} \mathrm{C}$, and terminated with a final extension step at $72{ }^{\circ} \mathrm{C}$ for $8 \mathrm{~min}$. Amplification products were separated on a $2 \%$ agarose gel stained with ethidium bromide and visualised under UV light.

\section{DNA sequencing}

To confirm the PCR results all positive PCR products were directly sequenced in two directions using the BigDye ${ }^{\circledR}$ Terminator method in an ABI 3730XL automatic DNA sequencer (Macrogen Europe, Amsterdam, The Netherlands). Sequence similarity analysis was performed using the BioEdit version 7.2.5 and Clustal W software. Sequence homology searches were made using the online version of BLAST software (available at http://blast.ncbi.nlm.nih.gov). Finally, the representative sequences were deposited into GenBank (accession numbers for T. equi: KY319140, KY319141, KY319142).

\section{Statistical analysis}

Haematological parameters were tested for normality by the KolmogorovSmirnov test and then analysed by Student's $t$-test or Mann-Whitney $U$-test for comparison between positive and negative animals. Statistical significance was assessed at the $0.05,0.01$ and 0.001 probability levels. Odds ratios with $95 \%$ confidence intervals were calculated according to Bland and Altman (2000). Statistical analysis of the results was done using software GraphPad Prism version 6.00 for Windows (GraphPad Software, San Diego, California, USA, www.graphpad.com).

\section{Results}

The prevalence of T. equi infection in the 70 donkeys tested with multiplex PCR was $50 \%$ (Fig. 2). Prevalence rates within herd are presented in Table 1. There was no B. caballi-positive sample or mixed infection.

Abnormal haematological alterations with respect to normal ranges were detected in 38 samples (54\%). Thirty-five of these donkeys (92\%) were found PCR positive for T. equi. Haematological alterations in PCR-positive samples included decreased RBC (35/35), decreased HCT (21/35), decreased HGB (14/35), increased MCH (11/35), increased MCHC (18/35), increased WBC (16/35), increased LYM (11/35), and decreased PLT (15/35). The chance (odds ratio) that haematocrit is lower than normal in donkeys positive for $T$. equi is 51 times higher (95\% confidence interval of 5.61-301.40) compared with donkeys negative for T. equi. The statistical differences between PCR positive and negative animals are shown in Table 2. 
Table 1

Intra-herd and total prevalence of Theileria equi and Babesia caballi using molecular testing

\begin{tabular}{llccc}
\hline Herd & Location & Number of donkeys & PCR prevalence of $T$. equi & PCR prevalence of $B$. caballi \\
\hline 1 & Zasavica & 25 & $64 \%(16 / 25)$ & $0 \%$ \\
2 & Stara planina & 25 & $48 \%(12 / 25)$ & $0 \%$ \\
3 & Kovilj & 20 & $35 \%(7 / 20)$ & $0 \%$ \\
\hline \multicolumn{2}{l}{ Total } & 70 & $50 \%(35 / 70)$ & $0 \%$ \\
\hline
\end{tabular}

Table 2

Statistical association of haematological parameters with PCR positivity for T. equi

\begin{tabular}{lccl}
\hline Parameters & $\begin{array}{c}\text { PCR-negative for T. equi } \\
\text { Mean (SD) }\end{array}$ & \multicolumn{2}{c}{$\begin{array}{c}\text { PCR-positive for T. equi } \\
\text { Mean (SD) }\end{array}$} \\
\hline WBC & $12.30(1.87)$ & $14.23(3.76)$ & $\mathrm{P}=0.0083^{* *}$ \\
LYM & $5.57(1.64)$ & $6.61(2.88)$ & $\mathrm{P}=0.054$ \\
MID & $0.40(0.35)$ & $0.40(0.41)$ & $\mathrm{P}=0.97$ \\
GRA & $6.16(1.99)$ & $7.23(3.44)$ & $\mathrm{P}=0.116$ \\
RBC & $7.21(0.46)$ & $6.01(0.63)$ & $\mathrm{P}=0.0001^{* * *}$ \\
HGB & $124.3(7.15)$ & $112.7(12.87)$ & $\mathrm{P}=0.0001^{* * *}$ \\
HCT & $37.94(2.45)$ & $30.41(4.73)$ & $\mathrm{P}=0.0001^{* * *}$ \\
MCV & $53.60(3.01)$ & $50.49(6.28)$ & $\mathrm{P}=0.0101^{* * *}$ \\
MCH & $17.45(0.89)$ & $18.87(2.18)$ & $\mathrm{P}=0.0007^{* * *}$ \\
MCHC & $326.4(8.41)$ & $378.3(56.32)$ & $\mathrm{P}=0.0001^{* * *}$ \\
PLT & $238.2(79.23)$ & $159(115.3)$ & $\mathrm{P}=0.0013^{* *}$ \\
\hline
\end{tabular}

$\mathrm{SD}=$ standard deviation. Statistical significance: ${ }^{*} \mathrm{P}<0.05 ;{ }^{* *} \mathrm{P}<0.01 ;{ }^{* * *} \mathrm{P}<0.001$

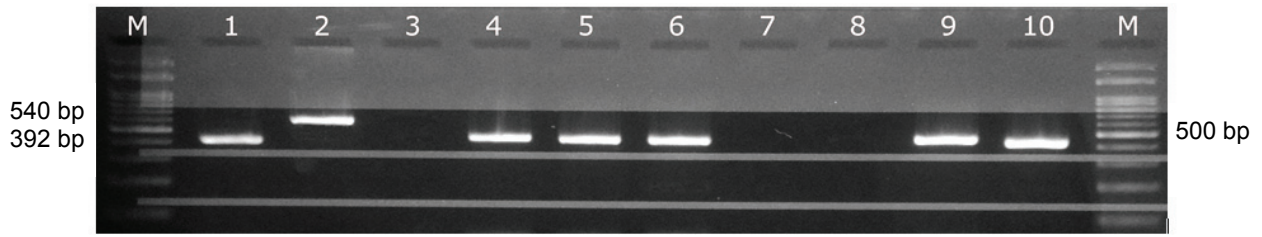

Fig. 2. Multiplex PCR detection of Theileria equi and Babesia caballi. M: 100-bp ladder DNA marker; lane 1: positive control for $T$. equi; lane 2: positive control for $B$. caballi; lane 3: negative control; lanes 4, 5, 6, 9 and 10: specimens infected with T. equi; lanes 7 and 8: negative specimens. The sizes of the positive bands are indicated on the left

Results of the sequence analysis demonstrated $100 \%$ correspondence to the species diagnosed by multiplex PCR. Sequences of the amplified DNA fragments were identical (391/391 bp) with the $18 \mathrm{~S}$ rRNA gene sequences of $T$. equi deposited in GenBank (GenBank accession no.: KR351291.1, KF559357.1 and JQ657703.1). 


\section{Discussion}

To the authors' knowledge, this is the first molecular survey of $T$. equi in donkeys from Serbia. The results show that T. equi is widespread in this region and can lead to evident haematological alterations.

All donkeys were asymptomatic at the time of blood sampling, which is in accordance with literature reports that EP infections in donkeys are in most cases subclinical or chronic, with non-specific signs (Kumar et al., 2009). Chronically infected animals may act as parasite carriers for tick transmission and facilitate the spread of this potentially severe disease in horses.

Molecular methods have previously been used to detect the DNA of $T$. equi and B. caballi in horse blood samples from Serbia (Davitkov et al., 2016). In this study the prevalence values based on molecular techniques differed depending on the sampling location. Although the differences were not statistically significant, the prevalence of $T$. equi was the highest in Zasavica (64\%). Such variations in prevalence between different sampling sites might be related to the presence of competent tick vectors, host activity or different climatic factors (Heim et al., 2007; Kouam et al., 2010; Grandi et al., 2011). The overall prevalence of $T$. equi-infected donkeys in our study was higher than that found in donkeys in Brazil (Machado et al., 2011) but lower than that reported from Iran and Italy (Abedi et al., 2015; Laus et al., 2015). In the present study, B. caballi infection was not detected in the blood samples of donkeys. This may be associated with the fact that infected equines completely eliminate $B$. caballi from their circulation after 1-4 years, while T. equi remains a life-long infection (de Waal and Van Heerden, 1994). Therefore, failure to detect B. caballi by PCR is perhaps due to parasite clearance from the blood by the host or the decrease of its presence to a level beyond the detection sensitivity of the molecular method used (Salim et al., 2008).

In agreement with our results, most epidemiological studies on EP showed a higher prevalence of $T$. equi compared with $B$. caballi infections in donkeys (Laus et al., 2015) as well as in horses (Bashiruddin et al., 1999; Criado-Fornelio et al., 2004; Nagore et al., 2004; Acici et al., 2008; Kouam et al., 2010; RosGarcía et al., 2013; Davitkov et al., 2016). The higher prevalence of equine theileriosis can be explained by the higher parasitaemia in the infected animals, the longer persistence of $T$. equi than B. caballi after infection, and the transplacental transmission of T. equi (de Waal and van Heerden, 1994; Allsopp et al., 2007; Georges et al., 2011).

Subclinical natural infections in donkeys included in this study seem to be associated with decreased RBC, HGB, HCT and PLT and with increased WBC, $\mathrm{MCH}$ and $\mathrm{MCHC}$. These results correspond well to the abnormalities reported in a recent study in Italy (Laus et al., 2015). The main haematological alterations in T. equi infections described in the present study were anaemia, leukocytosis, and 
thrombocytopenia. All these clinicopathological findings suggest the presence of a direct and immune-mediated pathogenic activity of the parasites. All infected animals had decreased RBC.

The present work showed that $T$. equi is prevalent among Balkan donkeys in Serbia. The identified haematological alterations in donkeys can lead to reduced working capacity and production performance. Veterinary examinations and health status monitoring are very important for preserving the Balkan donkey as an animal genetic resource. Also, infected donkeys act as parasite carriers and facilitate the spread of equine piroplasmosis, which has a major impact on international trade and on the horse industry. Further molecular research and long-term monitoring of equine piroplasmosis is needed in Serbia and throughout Europe.

\section{Acknowledgement}

This study, led by Professor Zoran Stanimirovic, was supported by the Ministry of Education, Science and Technological Development of the Republic of Serbia (Grant No. III46002).

\section{References}

Abedi, V., Razmi, Gh., Seifi, H. and Naghibi, A. (2015): Molecular detection of equine piroplasms in donkeys (Equus asinus) in North Khorasan province, Iran. Iran J. Vet. Res. 16, 202-204.

Acici, M., Umur, S., Guvenc, T., Arslan, H. H. and Kurt, M. (2008): Seroprevalence of equine babesiosis in the Black Sea region of Turkey. Parasitol. Int. 57, 198-200.

Alhassan, A., Pumidonming, W., Okamura, M., Hirata, H., Battsetseg, B., Fujisaki, K., Yokoyama, N. and Igarashi, I. (2005): Development of a single round and multiplex PCR method for the simultaneous detection of Babesia caballi and Babesia equi in horse blood. Vet. Parasitol. 129, 43-49.

Allsopp, M. T. E. P., Lewis, B. D. and Penzhorn, B. L. (2007): Molecular evidence for transplacental transmission of Theileria equi from carrier mares to their apparently healthy foals. Vet. Parasitol. 148, 130-136.

Bashiruddin, J. B., Camma, C. and Rebelo, E. (1999): Molecular detection of Babesia equi and Babesia caballi in horse blood by PCR amplification of part of the 16S rRNA gene. Vet. Parasitol. 84, 75-83.

Bland, J. M. and Altman, D. G. (2000): Statistics notes: the odds ratio. Br. Med. J. 320, 1468.

Criado-Fornelio, A., Gonzalez-del-Rio, M. A., Buling-Sarana, A. and Barba-Carretero, J. C. (2004): The 'expanding universe' of piroplasms. Vet. Parasitol. 119, 337-345.

Davitkov, D., Vucicevic, M., Stevanovic, J., Krstic, V., Slijepcevic, D., Glavinic, U. and Stanimirovic, Z. (2016): Molecular detection and prevalence of Theileria equi and Babesia caballi in horses of central Balkan. Acta Parasitol. 61, 337-342.

de Waal, D. T. and van Heerden, J. (1994): Equine Piroplasmosis. In: Coetzer, J. A. W. and Tustin, R. C. (eds) Infectious Diseases of Livestock, New York, Oxford University Press, pp. 425-433.

Georges, K. C., Ezeokoli, C. D., Sparagano, O., Pargass, I., Campbell, M. R., D’Abadie, R. and Yabsley, M. J. (2011): A case of transplacental transmission of Theileria equi in a foal in Trinidad. Vet. Parasitol. 175, 363-366. 
Grandi, G., Molinari, G., Tittarelli, M., Sassera, D. and Kramer, L. H. (2011): Prevalence of Theileria equi and Babesia caballi infection in horses from northern Italy. Vector Borne Zoonotic Dis. 11, 955-956.

Heim, A., Passos, L. M. F., Ribeiro, M. F. B., Costa-Junior, L. M., Bastos, C. V., Cabral, D. and Pfister, K. (2007): Detection and molecular characterization of Babesia caballi and Theileria equi isolates from endemic areas of Brazil. Parasitol. Res. 102, 63-68.

Kouam, M. K., Kantzoura, V., Gajadhar, A. A., Theis, J. H., Papadopoulos, E. and Theodoropoulos, G. (2010): Seroprevalence of equine piroplasms and host-related factors associated with infection in Greece. Vet. Parasitol. 169, 273-278.

Kumar, S., Kumar, R. and Sugimoto, C. (2009): A perspective of Theileria equi infections in donkeys. Jpn. J. Vet. Res. 56, 171-180.

Laus, F., Spaterna, A., Faillace, V., Veronesi, F., Ravagnan, S., Beribé, F., Cerquetella, M., Meligrana, M. and Tesei, B. (2015): Clinical investigation on Theileria equi and Babesia caballi infections in Italian donkeys. BMC Vet. Res. 11, 100.

Machado, R. Z., Toledo, C. Z. P., Teixeira, M. C. A., André, M. R., Freschi, C. R. and Sampaio, P. H. (2011): Molecular and serological detection of Theileria equi and Babesia caballi in donkeys (Equus asinus) in Brazil. Vet. Parasitol. 186, 461-465.

Mehlhorn, H. and Schein, E. (1998): Redescription of Babesia equi Laveran, 1901 as Theileria equi. Parasitol. Res. 84, 467-475.

Nagore, D., Garcia-Sanmartin, J., Garcia-Perez, A. L., Juste, R. A. and Hurtado, A. (2004): Detection and identification of equine Theileria and Babesia species by reverse line blotting: epidemiological survey and phylogenetic analysis. Vet. Parasitol. 123, 41-54.

Ros-García, A., M'ghirbi, Y., Hurtado, A. and Bouattour, A. (2013): Prevalence and genetic diversity of piroplasm species in horses and ticks from Tunisia. Infect. Genet. Evol. 17, 33-37.

Rothschild, C. M. (2013): Equine piroplasmosis. J. Equine Vet. Sci. 33, 497-508.

Salim, B. O., Hassan, S. M., Bakheit, M. A., Alhassan, A., Igarashi, I., Karanis, P. and Abdelrahman, M. B. (2008): Diagnosis of Babesia caballi and Theileria equi infections in horses in Sudan using ELISA and PCR. Parasitol. Res. 103, 1145-1150.

Stanisic, Lj., Dimitrijevic, V., Simeunovic, P., Lakic, N., Radovic, I., Ivankovic, A., Stevanovic, J. and Stanimirovic, Z. (2015): Morphological, biochemical and hematological characterization of endangered Balkan donkey breed. Acta Vet. Beograd 65, 125-136.

Wise, L. N., Kappmeyer, L. S., Mealey, R. H. and Knowles, D. P. (2013): Review of equine piroplasmosis. J. Vet. Intern. Med. 27, 1334-1346. 